\title{
Pre- and postvasectomy counseling: strategies to improve patient knowledge
}

This article was published in the following Dove Press journal:

Patient Intelligence

23 December 2015

Number of times this article has been viewed

\section{Brian T Nguyen \\ Section of Family Planning and Contraceptive Research, Department of Obstetrics and Gynecology, University of Chicago, Chicago, IL, USA}

Correspondence: Brian T Nguyen Department of Obstetrics and Gynecology, University of Chicago, 584I South Maryland Avenue, Chicago, IL 60637, USA

Email brian.trung.nguyen@gmail.com

\begin{abstract}
In the US, the primary providers of vasectomy are specialists who seldom introduce the idea of vasectomy to patients. Patients often come to the decision to have a vasectomy on their own or at the referral of their primary care provider (PCP). As patients rely on their PCPs for accurate information and referrals for treatment, the ability of PCPs to counsel their patients on the most appropriate methods of permanent contraception is essential. PCPs should know that vasectomy is simpler, faster, safer, cheaper, and at least equally effective as female sterilization. However, barriers to acceptability still exist, and male patients may have concerns and biases that PCPs need to be ready to address, ranging from anxieties about pain and sexual function post-procedure to the potential for regret and the development of certain cancers. This article provides an up-to-date review of the evidence on those aspects of vasectomy and may serve as a resource for providers to address patient concerns, and thus increase patient knowledge and uptake. Recommendations for home care and appropriate follow-up testing are included.
\end{abstract}

Keywords: vasectomy, male sterilization, contraception, contraceptive counseling

\section{Background}

That vasectomy continues to be used less frequently than female sterilization methods despite being simpler, faster, safer, ${ }^{1}$ cheaper, ${ }^{2,3}$ and at least equally effective as female sterilization, ${ }^{4-6}$ even in the setting of public health interventions to remove cost barriers, ${ }^{7}$ speaks to the need to address persistent and prevailing barriers to its acceptability. One of the most recent surveys of vasectomy uptake in the US from 2008 indicated that $17 \%$ of reproductive age women elected to undergo female sterilization, while only $6 \%$ of men underwent vasectomy, a difference of $>6.5$ million cases. ${ }^{8,9}$ Worldwide, the estimated reliance on vasectomy for contraception is $\sim 3 \%$, with cases of female sterilization outnumbering those of vasectomy by a factor of 15 in some countries. ${ }^{10}$ Increasing the uptake of vasectomy among couples seeking permanent contraception may alleviate significant reproductive and financial burdens borne both by women and health care systems. This article thus addresses knowledge barriers and provides updated evidence for improving both provider counseling and patient demand for vasectomy. As more than a third of physician referrals for vasectomy went unfulfilled in a US survey ${ }^{11}$ and as one-on-one counseling sessions have been shown to increase the acceptability of vasectomy, ${ }^{12}$ the information that patients receive from their primary providers may play a critical role in later uptake. 


\section{Physician responsibility: increasing awareness and acceptability}

As of $2002,75 \%$ of vasectomies in the US were performed by urologists. Accordingly, $90 \%$ of urology practices in the US provide vasectomy services. ${ }^{13}$ Given their case volume and experience, urologists are one of the patients' most reliable sources of information on vasectomy. However, patients often only meet urologists when they have already decided to undergo the procedure. While urologists can ensure patient's intraoperative and postoperative safety, they are seldom the physicians responsible for introducing vasectomy to patients. Instead, vasectomy is more often introduced to men by their partners or their primary care providers (PCPs) who then make a referral to urologists or other vasectomy-trained providers. Unfortunately, analyses of the US National Survey of Family Growth (NSFG) indicate that vasectomy was only discussed with $2.5 \%$ of American men reporting no intention to raise additional children; $;{ }^{14}$ counseling sessions with couples even show the routine omission of vasectomy, ${ }^{15}$ likely because no PCPs have assumed the routine responsibility of counseling men about their options for family planning. As PCPs may also believe that men are not interested in discussing family planning and resistant to the idea of a vasectomy, they may unwittingly limit information and access to vasectomy. ${ }^{16}$

The majority of contraceptive counseling is given by obstetrician-gynecologists (OB/GYNs) and family physicians. ${ }^{17}$ However, because OB/GYNs seldom provide vasectomy, they may be less knowledgeable about the specifics of the procedure and arranging for their provision; they therefore may feel less comfortable discussing and recommending vasectomy with female patients. Further, OB/GYNs may prioritize the provision of services to their patients in a timely manner and thus, recommend female sterilization given their ability to immediately schedule and provide the service, rather than make a referral. ${ }^{18}$ The number of family physicians trained to provide vasectomy has also dwindled, as a 2007 survey of family medicine training programs in the US showed that one-third $(33.7 \%)$ of chief residents cited the lack of a didactic training in vasectomy, with nearly half $(43.9 \%)$ not receiving adequate clinical training to provide vasectomy. ${ }^{19}$ Given the limited response rate (54\%) of this survey, it is possible that the proportion of family medicine physicians with sufficient experience to comfortably counsel their patients may be even lower.

Counseling from a health care provider can have a profound impact on contraceptive behaviors; ${ }^{20,21}$ doctors and nurses are the most influential sources of information on the decision to obtain a vasectomy. ${ }^{22}$ Consequently, ensuring that providers, regardless of specialty, understand the need to discuss vasectomy, are prepared to address preconceived notions, and provide thorough and accurate counseling is vital to the improvement of uptake..$^{22,23}$ The American College of Obstetrics and Gynecologists has thus released practice recommendations stating specifically that women should be informed about vasectomy as an alternative to female sterilization that "is safer, more effective, and less expensive". Though educating physicians who predominantly see female patients about vasectomy may seem counterintuitive, suggestion to undergo vasectomy by a man's female partner/wife is a key factor in uptake. ${ }^{22}$ Women's health providers may also encounter men during their female patients' prenatal care or after the delivery of a couple's last intended child, at which point a discussion of vasectomy may be appropriate and well timed. OB/GYNs and family physicians may also be the only providers of vasectomy in underserved areas without urologists. ${ }^{24}$ Ensuring the continued exposure to vasectomy counseling and procedures may thus be a valuable endeavor for medical schools and residency training programs focused on the development of primary care physicians. Conversely, vasectomy providers may benefit from the continued development of their contraceptive knowledge in the event that vasectomy may not be an appropriate method of contraception for some of their patients.

\section{Physician responsibility: addressing men's major concerns}

Beyond increasing access and awareness, physicians need to address the major concerns that keep men from even considering vasectomy as an option. Men may be comforted to know that the risk of death related to vasectomy is close to zero given only a single reported case in the medical literature of Fournier's gangrene in 1992. ${ }^{25}$ Some men are concerned about long-term health effects that may result from vasectomy due to the formation of anti-sperm antibodies and related immune complexes that were suspected to increase the risk of arterial plaques or tissue damage. ${ }^{26}$ However, concerns about the risk of cardiovascular disease (eg, hypertension, angina, myocardial infarction, stroke), autoimmune disorders, and various andrologic cancers (eg, testicular, prostate) have all been dispelled by more recent, well-designed, large-scale studies even taking into account time since vasectomy. Though the American Urological Association (AUA) has stated that these concerns need not be routinely discussed in pre-vasectomy counseling given that vasectomy has not been found to be a risk factor, ${ }^{27}$ some men may still require reassurance. 
Concerns about sexual function after a vasectomy also continue to be a major barrier to uptake, one survey even reporting it to be the leading reason for couples' decisions to undergo female sterilization instead. ${ }^{28}$ Some men believe that the procedure will interrupt the transmission of spermatic fluid, resulting in the loss of ejaculation during sexual intercourse, potentially affecting sexual pleasure for both partners. ${ }^{12}$ As few men are willing to discuss sexual concerns directly with health care providers given fear of stigma, health care providers should consider offering to start these discussions with men. Providers may be reassured to know that men from even the most conservative societies appreciate frank discussions of sexual function and pleasure when they are initiated by health care providers, with some even asserting, "this is exactly what I wanted to know". ${ }^{12}$ Providers should explicitly clarify for their patients that vasectomy only prevents the inclusion of sperm in semen (produced by the seminal vesicles and the prostate gland) and that erection, ejaculation, and orgasm occur normally. Providers can reassure men that multiple studies also refute the association of vasectomy and sexual dysfunction, attributing reports of dysfunction to psychosocial disturbances instead. ${ }^{29-31}$ The most recent survey of the NSFG from 2006 to 2008 even examined sexual frequency among men who had undergone vasectomy, finding that the average frequency of sexual intercourse was not significantly different for those who had a vasectomy compared to those who had not received a vasectomy (5.9 times per month vs 4.9 times per month, respectively). ${ }^{32}$ Furthermore, men may appreciate that surveys of female partners before and after their partners' receipt of vasectomy showed significant improvements in female sexual desire, arousal, orgasm, lubrication, and satisfaction, possibly related to the confidence that they would not get pregnant. ${ }^{33}$

\section{Pre-procedural counseling: procedure and pain}

Concerns about the pain and surgical risk involved in vasectomy may stem from the negative experiences of previous generations who underwent incisional vasectomies that required one to two incisions and stitching on the scrotum. Consequently, it is important for health care providers to inform patients about contemporary practices that have reduced both pain and the risks associated with the procedure. The most significant modification to vasectomy was the development of the no-scalpel vasectomy technique in 1974. The technique incorporates a vasal nerve block using local anesthetic, followed by isolation of the vas deferens at the level of the skin with a ringed clamp. Sharply pointed forceps then spread and dissect superficial tissue layers and expose the vas deferens for excision/ligation. No stitches are needed upon completion of the procedure, ${ }^{34}$ which often takes approximately half an hour. The method gained popularity and was disseminated worldwide in the 1980s. ${ }^{35}$ At the turn of the 21st century, the Madajet air-injection system was introduced, allowing the simultaneous administration of local anesthetic to the vas deferens and overlying skin - a method for minimally painful, minimally damaging, no-scalpel, noneedle vasectomy was thus described ${ }^{36,37}$ Following the initial pain from the injection of local anesthetic, men generally feel only the pulling and stretching of the scrotum and spermatic cord. Compared to incisional vasectomy, no-scalpel, no-needle vasectomy has lower rates of bleeding, hematoma formation, and infection at $1 \%-2 \%$ of cases. ${ }^{38}$

A unique complication of vasectomy that should be discussed is the potential development of chronic unilateral or bilateral scrotal/testicular pain, thought to occur among 1\% of vasectomized men. ${ }^{39}$ The pain can be a dull, throbbing pain that radiates from the scrotum to the perineum and inner thigh. In some cases, the pain may be related to obstruction of the vas deferens, the development of a sperm granuloma, or an idiopathic epididymitis. Although the condition can be alleviated by anti-inflammatories, surgical drainage, or vasovasostomy (vasectomy reversal), these interventions may not always fully improve the pain. ${ }^{40}$ Providers should screen patients for any preoperative scrotal discomfort as this has been noted to be a risk factor for the development of chronic postvasectomy pain. ${ }^{41}$

Regardless of the information that men receive from providers about the safety of vasectomy and the measures taken to ensure their comfort during the procedure, patients may continue to report anxiety to the extent that they request sedation. The anecdotal experience of many providers however is that anxiolytics are not routinely offered prior to vasectomy, as they are rarely needed and seldom show improvement in the patient's anxiety when compared to good rapport and communication between the physician and patient during the procedure.

\section{Pre-procedural counseling: patient selection}

While developments in the safety, efficacy, and even potential reversibility of vasectomy may lead to a rise in the number of men desiring the procedure, not all men will be good candidates for vasectomy given the risk of regret. The AUA's guidelines on vasectomy provision state 
that "vasectomy is intended to be a permanent form of contraception". The AUA thus recommends a preoperative appointment either in-person or by telephone/electronic communication prior to vasectomy to ascertain their understanding of this important concept. ${ }^{42}$ Though vasectomies can be reversed or sperm retrieved from the testes for the purposes of in vitro fertilization, these options are less successful with time and can be expensive. ${ }^{43} \mathrm{~A}$ review of men who had undergone vasectomy from the NSFG showed that $\sim 20 \%$ listed a desire to have future children at the time of the survey. That the survey also demonstrated that $\sim 2 \%$ of vasectomized men had undergone a reversal suggests that a number of men may not have ever considered the permanency of vasectomy or had encountered a life-altering event leading to their regret. ${ }^{44}$ Other surveys measuring reports of regret alone suggest its incidence in up to $10 \%$ of couples. ${ }^{45}$ Selection of the right candidate for vasectomy, with the lowest risk of regret or providing high-risk patients with comprehensive counseling, is thus critical.

One of the greatest risks for regret after vasectomy is the patient's age at the time of the procedure. The desire for children among some men increases with time from the procedure; consequently, men who undergo vasectomy before the age of 30 carry more than ten times the odds of later undergoing vasectomy reversal. ${ }^{46}$ Due to increased odds of regret, some providers will not provide vasectomies to patients under the age of 30 or to patients who have not had children; however, these policies are uncommon. As men desiring a vasectomy are likely to move from provider to provider in order to obtain the procedure they desire, some providers opt to undergo thorough counseling sessions with these patients instead, addressing their expectations and such possibilities as complications to a current pregnancy, the death of a child/loved one, dissolution of a relationship, or change in personal beliefs over time. Though some providers require men to undergo a waiting period to consider their decision, this practice is also uncommon as men are believed to have given significant thought to these decisions. ${ }^{42}$ Given the lack of time during an appointment to discuss many of the above issues, some providers have introduced informational decision-making aids into their practices that inform patients about the procedure, educate about alternative methods of contraception, and help men clarify their readiness for permanent contraception. These decision-making aids have helped men become more comfortable with their decisions, ${ }^{47}$ which may have a long-term impact on their satisfaction.

\section{Post-procedure counseling: precautions and instructions}

After receipt of their procedures, all patients should receive precautions and instructions for postoperative care. Patients should be recommended to apply ice or cold packs to the scrotum, wear supportive underwear to alleviate pain related to tension on the spermatic cord, and use nonsteroidal antiinflammatory medications such as ibuprofen immediately following the procedure. The surgical site should always be kept clean and dry with showers permitted only on the following day and any full immersion in water to be avoided for 1 week. Bruising and swelling are to be expected, and patients should be instructed to call for any fevers, swelling, increasing redness, or excess bleeding or discharge.

Though the large majority of patients do well after their vasectomies and are able to leave immediately, syncopal episodes do occur, and patients should be monitored for any signs of instability prior to being allowed to drive home; having someone else to accompany the men to their visit and drive them home is a safe alternative. Some patients return to work on the day of the procedure if performing non-strenuous activity. Men with more physical jobs may wait to return to work until they are pain free with movement.

Regarding ejaculation, patients are advised to abstain for 1 week following their procedures to allow healing and full occlusion of the cut ends of the vas deferens. Though men can safely ejaculate after the first week, patients need to be advised that vasectomy does not produce immediate sterility and that another form of contraception is warranted until complete occlusion can be verified via a semen analysis that shows either 1) azoospermia, or 2) <100,000 nonmotile sperm per milliliter of semen. Depending on a patient's age, frequency of ejaculation, and anatomical variations, reaching azoospermia can take anywhere from 3 weeks to 3 months, and patients should continue to follow up with their providers until they can obtain confirmation; otherwise, they may require another procedure. ${ }^{48}$ The need for semen analyses should be emphasized given previous studies showing that up to a quarter of men never return for confirmatory testing despite instruction. ${ }^{49,50}$ Though occlusion techniques, including cauterization of the lumen of the vas deferens and burial of its abdominal end within the overlying fascial sheath, have decreased failure rates of vasectomy to $<0.5 \%,{ }^{38,42,51}$ unplanned pregnancies have been documented and are more likely to occur within the first months of a vasectomy, likely among men who had never confirmed the success of their operations. ${ }^{52}$ Nevertheless, even after confirmation of occlusion of the vas deferens, patients should be counseled 
about the nonzero risk of pregnancy given the potential for recanalization.

\section{Conclusion}

As vasectomy is safer, cheaper, and at least equally effective as methods of female sterilization, physicians should work to improve patient awareness of the procedure and counsel to increase its acceptance. Patient concerns about health risks, sexual function, and operative pain remain significant barriers to the uptake of vasectomy; however, these risks have been well researched and noted to be minimal or even unfounded. In order for patients to receive this information however, initiation of conversations about contraception with men is required, which is often neglected. PCPs should discuss reproductive health with both male and female patients. Furthermore, although $\mathrm{OB} /$ GYNs mainly see female patients, they may recommend vasectomy to couples when discussing postpartum contraception or to women considering sterilization. As health care providers are one of the most trusted resources for contraceptive information, their advocacy for the procedure may be one of the best strategies to improve patient knowledge and uptake of vasectomy. After providing their procedures, providers should also encourage their patients to promote vasectomy, as men who speak from personal experience may be the most effective advocates of the method. Ensuring that these patients have received comprehensive counseling will allow them to dispel the deep-seated concerns of their peers and help to overcome a significant sex disparity in reproductive health and family planning.

\section{Disclosure}

Dr Nguyen serves on the medical advisory board for the Female Health Company, the products and services of which are unrelated to the content discussed in this article. The author reports no other conflicts of interest in this work.

\section{References}

1. Trussell J, Leveque JA, Koenig JD, et al. The economic value of contraception: a comparison of 15 methods. Am J Public Health. 1995;85(4):494-503.

2. Shih G, Turok DK, Parker WJ. Vasectomy: the other (better) form of sterilization. Contraception. 2011;83(4):310-315.

3. Trussell J. Update on and correction to the cost-effectiveness of contraceptives in the United States. Contraception. 2012;85(6):611.

4. Jamieson DJ, Costello C, Trussell J, et al. The risk of pregnancy after vasectomy. Obstet Gynecol. 2004;103(5 Pt 1):848-850.

5. Carignan CS, Pati S. Tubal occlusion failures: implications of the CREST study on reducing the risk. Medscape Womens Health. 1997;2(11):1.

6. American College of Obstetricians and Gynecologists. ACOG Practice bulletin no 133: benefits and risks of sterilization. Obstet Gynecol. 2013;121(2 Pt 1):392.

7. Garg PK, Jain BK, Choudhary D, et al. Nonscalpel vasectomy as family planning method: a battle yet to be conquered. ISRN Urol. 2013;2013:752174.
8. Mosher WD, Jones J. Use of contraception in the United States: 1982-2008. Vital Health Statistics. Series 23. 2010;(29):1-44.

9. Anderson JE, Jamieson DJ, Warner L, et al. Contraceptive sterilization among married adults: national data on who chooses vasectomy and tubal sterilization. Contraception. 2012;85(6):552-557.

10. Pile JM, Barone MA. Demographics of vasectomy - USA and international. Urol Clin North Am. 2009;36(3):295-305.

11. Thiel de Bocanegra H, Riedel JC, Menz M, et al. Onsite provision of specialized contraceptive services: does title $\mathrm{X}$ funding enhance access? J Womens Health. 2014;23(5):428-433.

12. Singh H, Mishra A, Alam D, et al. Increasing male participation in the uptake of vasectomy services. J Fam Plann Reprod Health Care. 2014;40(1):64-65.

13. Barone MA, Hutchinson PL, Johnson $\mathrm{CH}$, et al. Vasectomy in the United States, 2002. J Urol. 2006;176(1):232-236; discussion 36.

14. Borrero S, Moore C, Creinin M, et al. Low rates of vasectomy among minorities: a result of differential receipt of counseling? Am J Mens Health. 2010:4(3):243-249.

15. Shih G, Dubé K, Dehlendorf C. "We never thought of a vasectomy": a qualitative study of men and women's counseling around sterilization. Contraception. 2013;88(3):376-381.

16. Landry E, Ward V. Perspectives from couples on the vasectomy decision: a six-country study. In: Beyond Acceptability: Users' Perspectives on Contraception. World Health Organization. Reproductive Health Matters. 1997:58-67.

17. Young EE, Nguyen BT, Weiss-Laxer NS, et al. Factors associated with family planning and vasectomy discussions: results from a health provider survey. Med Health R I. 2010;93(2):48-50.

18. Haws JM, McKenzie M, Mehta M, et al. Increasing the availability of vasectomy in public-sector clinics. Fam Plann Perspect. 1997;29(4): 185-186, 190.

19. Herbitter C, Greenberg M, Fletcher J, et al. Family planning training in US family medicine residencies. Fam Med. 2011;43(8):574-581.

20. Lee JK, Parisi SM, Akers AY, et al. The impact of contraceptive counseling in primary care on contraceptive use. J Gen Intern Med. 2011;26(7):731-736.

21. Lamvu G, Steiner MJ, Condon S, et al. Consistency between most important reasons for using contraception and current method used: the influence of health care providers. Contraception. 2006;73(4): 399-403.

22. Barone MA, Johnson CH, Luick MA, et al. Characteristics of men receiving vasectomies in the United States, 1998-1999. Perspect Sex Reprod Health. 2004;36(1):27-33.

23. Miller WB, Shain RN, Pasta DJ. Tubal sterilization or vasectomy: how do married couples make the choice? Fertil Steril. 1991;56(2):278-284.

24. Simon JR, Stier EA. If a man needs a gynecologist, will he be able to find one? Ann Intern Med. 2014;160(8):570-571.

25. Viddeleer AC, Lycklama a Nijeholt GA. Lethal Fournier's gangrene following vasectomy. J Urol. 1992;147(6):1613-1614.

26. Perrin EB, Woods JS, Namekata T, et al. Long-term effect of vasectomy on coronary heart disease. Am J Public Health. 1984;74(2):128-132.

27. Kohler TS, Fazili AA, Brannigan RE. Putative health risks associated with vasectomy. Urol Clin North Am. 2009;36(3):337-345.

28. Thompson B, MacGillivray I, Fraser C. Some factors in the choice of male or female sterilisation in Aberdeen. J Biosoc Sci 1991;23(3): 359-363.

29. Smith A, Lyons A, Ferris J, et al. Are sexual problems more common in men who have had a vasectomy? A population-based study of Australian men. $J$ Sex Med. 2010;7(2 Pt 1):736-742.

30. Hofmeyr DG, Greeff AP. The influence of a vasectomy on the marital relationship and sexual satisfaction of the married man. J Sex Marital Ther. 2002;28(4):339-351.

31. Buchholz NP, Weuste R, Mattarelli G, et al. Post-vasectomy erectile dysfunction. J Psychosom Res. 1994;38(7):759-762.

32. Guo DP, Lamberts RW, Eisenberg ML. Relationship between vasectomy and sexual frequency. $J$ Sex Med. 2015;12(9):1905-1910.

33. Mohamad Al-Ali B, Shamloul R, Ramsauer J, et al. The effect of vasectomy on the sexual life of couples. J Sex Med. 2014;11(9): 2239-2242. 
34. Coe TM, Curington J. An inexpensive yet realistic model for teaching vasectomy. Int Braz J Urol. 2015;41(2):373-378.

35. Gonzales B, Marston-Ainley S, Vansintejan G, et al. No-Scalpel Vasectomy: An Illustrated Guide for Surgeons. Engender Health. New York. 1992

36. Weiss RS, Li PS. No-needle jet anesthetic technique for no-scalpel vasectomy. J Urol. 2005;173(5):1677-1680.

37. Wilson CL. No-needle anesthetic for no-scalpel vasectomy. Am Fam Physician. 2001;63(7):1295.

38. Labrecque M, Dufresne C, Barone MA, et al. Vasectomy surgical techniques: a systematic review. BMC Med. 2004;2:21.

39. Leslie TA, Illing RO, Cranston DW, et al. The incidence of chronic scrotal pain after vasectomy: a prospective audit. BJU Int. 2007; 100(6):1330-1333.

40. Adams CE, Wald M. Risks and complications of vasectomy. Urol Clin North Am. 2009;36(3):331-336.

41. Keoghane SR, Sullivan ME. Investigating and managing chronic scrotal pain. BMJ. 2010;341:c6716.

42. Sharlip ID, Belker AM, Honig S, et al. Vasectomy: AUA guideline. J Urol. 2012;188(6 Suppl):2482-2491.

43. Fuchs EF, Burt RA. Vasectomy reversal performed 15 years or more after vasectomy: correlation of pregnancy outcome with partner age and with pregnancy results of in vitro fertilization with intracytoplasmic sperm injection. Fertil Steril. 2002;77(3):516-519.
44. Sharma V, Le BV, Sheth KR, et al. Vasectomy demographics and postvasectomy desire for future children: results from a contemporary national survey. Fertil Steril. 2013;99(7):1880-1885.

45. Miller WB, Shain RN, Pasta DJ. The pre- and poststerilization predictors of poststerilization regret in husbands and wives. J Nerv Ment Dis. 1991;179(10):602-608.

46. Potts J, Pasqualotto F, Nelson D, et al. Patient characteristics associated with vasectomy reversal. J Urol. 1999;161(6):1835-1839.

47. Labrecque M, Paunescu C, Plesu I, et al. Evaluation of the effect of a patient decision aid about vasectomy on the decision-making process: a randomized trial. Contraception. 2010;82(6):556-562.

48. Eisenberg ML, Henderson JT, Amory JK, et al. Racial differences in vasectomy utilization in the United States: data from the national survey of family growth. Urology. 2009;74(5):1020-1024.

49. Dhar NB, Bhatt A, Jones JS. Determining the success of vasectomy. BJU Int. 2006;97(4):773-776.

50. Griffin T, Tooher R, Nowakowski K, et al. How little is enough? The evidence for post-vasectomy testing. J Urol. 2005;174(1):29-36.

51. Cook LA, Van Vliet HA, Lopez LM, et al. Vasectomy occlusion techniques for male sterilization. Cochrane Database Syst Rev. 2014;3:CD003991.

52. Belker AM, Sexter MS, Sweitzer SJ, et al. The high rate of noncompliance for post-vasectomy semen examination: medical and legal considerations. J Urol. 1990;144(2 Pt 1):284-286.
Patient Intelligence

\section{Publish your work in this journal}

Patient Intelligence is an international, peer-reviewed, open access journal that characterizes and measures the central role of patient behavior and intention in optimizing healthcare management in all areas of disease and complaint types. An improved understanding of patient intelligence coupled with predictive analysis helps an organization contribute more effectively to achieving better outcomes.

Submit your manuscript here: http://www.dovepress.com/patient-intelligence-journal

\section{Dovepress}

The journal is characterized by the rapid reporting of reviews, original research, methodologies, analytics, modeling, clinical studies and patient surveys across all disease areas. The manuscript management system is completely online and includes a very quick and fair peer-review system. Visit http://www.dovepress.com testimonials.php to read real quotes from published authors. 